\title{
Pretense and imagination
}

\author{
Shen-yi Liao ${ }^{1}$ and Tamar Szabó Gendler²*
}

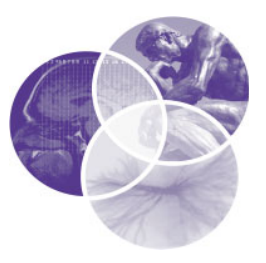

\begin{abstract}
Issues of pretense and imagination are of central interest to philosophers, psychologists, and researchers in allied fields. In this entry, we provide a roadmap of some of the central themes around which discussion has been focused. We begin with an overview of pretense, imagination, and the relationship between them. We then shift our attention to the four specific topics where the disciplines' research programs have intersected or where additional interactions could prove mutually beneficial: the psychological underpinnings of performing pretense and of recognizing pretense, the cognitive capacities involved in imaginative engagement with fictions, and the real-world impact of make-believe. In the final section, we discuss more briefly a number of other mental activities that arguably involve imagining, including counterfactual reasoning, delusions, and dreaming. (c) 2010 John Wiley \& Sons, Ltd. WIREs Cogn Sci 20112 79-94 DOI: 10.1002/wcs.91
\end{abstract}

\section{INTRODUCTION}

$\mathrm{I}_{\mathrm{t} \text { sil }}$ ssues of pretense and imagination are of central interest to philosophers, psychologists, and researchers in allied fields. In this entry, we provide a roadmap of some of the central themes around which discussion has been focused.

We begin with an overview of pretense, imagination, and the relationship between them in the section entitled Imagination and Pretense. We then shift our attention to four specific topics where the disciplines' research programs have intersected or where additional interactions could prove mutually beneficial: The Cognitive Underpinnings of Pretense, Recognition of Pretense, Imaginative Engagement with Fictions, and The Real-World Impact of Make-Believe. In the final section (Other Roles for the Imagination), we discuss more briefly a number of other mental activities that arguably involve imagining, including counterfactual reasoning, delusions, and dreaming.

\section{IMAGINATION AND PRETENSE}

The term 'imagination' is a broad one; in this entry, we focus primarily on the sense required for pretend play and engagement with fictions. As a first pass, imagination in this sense is the capacity that underpins our ability to simulate perspectives that differ from the

\footnotetext{
*Correspondence to: tamar.gendler@yale.edu

${ }^{1}$ University of Michigan, Ann Arbor, MI

${ }^{2}$ Yale University, New Haven, CT, USA

DOI: $10.1002 /$ wcs.91
}

one available to us through experience. Other terms used to advert to this capacity include 'make-belief', ${ }^{1}$ 'pretense', 2 'possible worlds box', ${ }^{3}$ and 'recreative imagination'. 4

Imagination in this sense-recreative imagination-can be contrasted with sensory imagination and creative imagination (following Currie and Ravenscroft ${ }^{4}$; cf. Strawson ${ }^{5}$ ). Roughly, sensory imagination is the capacity to have perception-like experiences in the absence of relevant stimuli; it is often voluntary, controlled, and willful. Creative imagination is the capacity to combine ideas in unexpected and unconventional ways. Although these capacities may be invoked in pretend play and engagement with fictions, it is recreative imagination that drives makebelieve activity itself.

Imagination in our sense can also be distinguished from a number of related states. Recreative imaginings have representational content, which is lacking in (simple) emotions or purely affective states. And in representing some state of affairs as being the case, recreative imagining is unlike conative attitudes such as desiring, wanting, wishing, and hoping, which do not represent their target in that way. (Note, however, that some philosophers think that an imaginative analogue of desire is necessary to explain certain aspects of pretense; cf. Currie and Ravenscroft ${ }^{4}$ and Doggett and Egan. ${ }^{6}$ )

In these respects, recreative imagination is a belief-like state: indeed, some have argued that imagination and belief share a 'single code', in the sense that the same cognitive mechanisms are employed in processing both imaginings and beliefs, and beliefs and imaginings with similar content are processed in 
similar ways. ${ }^{7,8}$ Despite these similarities, however, imagination and belief differ in both functional and normative ways. Functionally, whereas belief is typically connected, in conjunction with desire, to the motivation of behavior, imagination is typically not. Normatively, whereas belief is governed by a norm of truth, imagination is not. Indeed, to understand what it is to imagine or pretend may require understanding that one is not merely believing falsely. ${ }^{9}$

In the sense just specified, imagination and pretense are closely tied. Just how closely is to some extent a terminological matter. Some (following Ryle ${ }^{10}$ ) speak of imagination and pretense interchangeably; others take imagination to be more mentalistic and pretense more behavioral. On the latter reading, most philosophers agree that one could imagine without pretending, and some contend that one could pretend without imagining. ${ }^{4}$

In our discussion below, unless otherwise indicated, we will use the term imagination in its recreative sense, and the term pretense in its behavioral sense.

\section{THE COGNITIVE UNDERPINNINGS OF PRETENSE}

In this section, we focus on the (conscious or unconscious) performance of pretense: we present the developmental timeline of the underlying ability, say a few words about the apparent relationship between pretense and mindreading or theory of mind, and describe a number of leading theories of pretense. In the next section, Recognition of Pretense, we address issues having to do with the recognition (and indication) of pretense. Though the capacities for performance and recognition are conceptually distinct, they are closely tied developmentally and cognitively.

\section{Developmental Timeline}

Before the middle of their second year-often by 15 months-typically developing children show indications of what appears to be make-believe play. For example, they may act as if an ordinary piece of cloth were their special bedtime pillow, while giggling in a playful fashion. (Arguably, instances of unconscious symbolic representation occur much earlier-see Piaget. ${ }^{11}$ )

By 22 months, these skills become quite widespread $^{2,12}$ and by $24-28$ months, most children are able to participate fully in explicit games of makebelief-for example, pouring 'tea' from an empty plastic teapot, feeding a toy pig some 'cereal' from an empty bowl, giving a stuffed monkey a 'banana' when there are no (real) bananas in sight, and so on. , $^{2,13}$
At the beginning of the third year (24-28 months), four important capacities develop that allow children to engage in sophisticated joint pretend play and pretend play involving props. Following Harris, ${ }^{2}$ these are:

\section{Stipulation-initiation}

Pretense content may be generated by stipulations. (So, for example, blue blocks may be deemed to be 'cars' and red blocks to be 'trucks'.) The mapping rules between the imaginary scenario and reality may be instituted by fiat, tend to be spontaneously extended to related objects, and tend to be episodically circumscribed (cf. Walton ${ }^{1}$ ).

\section{Inheritance of Causal Powers}

Many of the causal powers of represented object are mapped onto the prop. (So, for example, if a blue block 'hits' a 'tree', the 'tree' will be 'uprooted'.)

\section{Suspension of Concern for Actual Features}

In many cases, the pretend features are taken to override conflicting actual features: children engaging in pretense tend to draw inferences from the stipulations (the teapot is 'full' so the counter will become 'wet') rather than from objective features of the world (the teapot is empty, so no wetness will be transmitted).

\section{Production of Linked Causal Chains}

The results of previous pretend transformations may feed into later transformations. Children engaging in pretense often construct narratives that include a series of linked causal chains, demonstrating a capacity to make a series of inferences based on the pretend causal properties that the props take on.

During their fourth year, most children develop the capacity to engage in complex coordinated games of joint pretense with others. ${ }^{15}$ By the age of 4, they have figured out how to keep track of different individuals simultaneously engaging in different games of pretense (recognizing, for instance, that if you pretend the pebbles are apples and I pretend the pebbles are plums, you will be baking an apple cake while I am baking a plum cake. ${ }^{15}$

Because of the near-universality of this developmental trajectory, deviations from it can serve as a basis for theoretical work regarding pretense's wider role. Some of this work is discussed in the next subsection in the context of mindreading and autism.

\section{Pretense and Mindreading/Theory of Mind}

Mindreading or theory of mind is the activity of attributing mental states to oneself and to others, 
and of predicting and explaining behavior on the basis of those attributions. A number of philosophers and psychologists have suggested that the mechanisms underlying subjects' capacity to pretend are the same ones that allow them to engage in mindreading (see Refs 3, 4, 7, 16, and 17; for an overview of recent discussions, see Ref 18). Because pretense requires imaginatively taking up alternative perspectives, the same abilities could also contribute to understanding the actual perspectives of other people. Evidence from atypical developmental trajectories, particularly autism, appears to offer empirical support for this hypothesis: lack of spontaneous pretense in children on the autistic spectrum tends to be correlated with deficits in empathy and perspective-taking. ${ }^{4,16,19-21}$

Early discussions of mindreading were often framed as debates between the 'theory theory' and the 'simulation theory'. (Influential collections of papers on this debate include Carruthers and Smith $^{22}$ and Davies and Stone. ${ }^{23,24}$ ) On theory theory views, mindreading involves the application of some (tacit) folk psychological theory that allows the subject to make predictions and offer explanations of the target's beliefs and behaviors (for early discussions, see Refs 25-27; for overview, see Ref 28). On simulation theory views, mindreading involves simulating the target's mental states so as to exploit similarities between the subject's and target's processing capacities. It is this simulation that allows the subject to make predictions and offer explanations of the target's beliefs and behaviors. (For early discussions, see Refs 29-31; for recent dissent, see, e.g., Refs 18, 32-34; for overview, see Ref 35.)

In recent years, proponents of both sides have increasingly converged on common ground, allowing that both theory and simulation play some role in the attribution of mental states to others. Goldman, ${ }^{16}$ for example, argues that while simulation is the primary means by which the reading of minds is accomplished, theorizing plays a role in certain sorts of cases as well. Many recent discussions have endorsed some such hybrid view, with more or less weight given to each of the components in particular cases (cf. Refs 3 and 36). On such views, the capacity for recreative imagination is often held to play a central role in enabling mindreading.

\section{Theories of Pretense}

Theories of pretense fall into three main families. Metarepresentational views hold that it is the concept PRETEND that underlies the ability to engage in pretend play. ${ }^{7,37}$ Behaviorist views hold that the ability to engage in pretend play is driven by a process of behaving-as-if. ${ }^{3,38-40}$ Intentionalist views hold that to engage in pretense requires behaving-as-if plus the intention to do so; people act-as-if rather than behaveas-if. ${ }^{41,42}$

Metarepresentational views claim that what is central to pretense is mentalistic: treating pretense as such. What underlies the capacity for treating pretense as such-being able to perform pretense and recognize pretense-is the possession of the concept PRETEND. Roughly, to pretend is to represent one's own representations, and so the concept PRETEND applies to metarepresentations. Mechanistically speaking, a decoupler mechanism (described below) is what allows the formation, manipulation, and interpretation of these metarepresentations (Ref 7, pp. 419-420). Metarepresentationalism is often associated with its original proponent and continual defender, Alan Leslie (for example, see Refs 7, 19, 37, and 43).

One initial attraction of the view is that it explains how the processing of pretense representations, such as inferring, might utilize the same mechanisms that are employed in genuine representations: that is, it offers the promise of a 'single code' (Ref 7, p. 417). On this sort of view, subjects have a decoupler mechanism that extracts the pretense representation and allows it to be processed by the same mechanisms, such as inference, that process genuine representations. Another initial attraction of the view is that the same mechanism it proposes for pretense, the representation decoupler, also explains the representational structures necessary for theory of mind (Ref 7, p. 423). In service of pretense, the decoupler allows for representations of one's own representations, and in service of theory of mind, the decoupler allows for representations of others' representations. Research about autistic children's simultaneous deficiencies in pretend play and theories of mind gives further evidence for their common involvement of metarepresentations. ${ }^{19}$

A number of the features of Leslie's account have been co-opted by subsequent behaviorist views. For example, Nichols and Stich ${ }^{3}$ incorporate Leslie's idea that belief and imagination operate on a 'single code' and that the same mechanism-for Nichols and Stich, a possible worlds box rather than Leslie's decoupler-underlies the capacity for pretend play and theory of mind. By incorporating many of Leslie's earlier insights, later behaviorist theories are also able to adequately explain the performance of pretense and account for many observations of the pretense developmental trajectory. Gradually, the difference between the two appears to turn on predictions they 
make about recognition of pretense, which we will describe in the next section. ${ }^{37,43}$

Behaviorist views claim that what is central to pretense is behavioral: behaving 'as-if' a scenario obtains (or rather, behaving in a way that would be appropriate if that scenario obtained). Which capacities underlie the ability to behave-as-if is contentious. Following a categorization initially made in Ref 38, suppositional views like Perner's ${ }^{40}$ and Nichols and Stich's ${ }^{3}$ claim that it is the ability to make representations with a counterfactual attitude, and proto-simulationist views like Harris's ${ }^{2,13}$ claim that it is some precursor to the ability of putting oneself in another's shoes. Both variants of behaviorism agree, though, that pretense does not require possessing the concept PRETEND or the capacity to generate metarepresentations.

Behaviorists argue that evidence from the same domains that Leslie focused on-developmental timeline, relation to theories of mind, and autism-either does not unambiguously support metarepresentational views, or in fact better supports their views. ${ }^{38}$ Overall, the evidence seems to be mixed.

Regarding the developmental timeline, one key prediction of metarepresentational theories is that solo pretend play and understanding pretend play in others should develop at about the same time. As critics point out, however, the empirical evidence here is ambiguous. ${ }^{12}$

With respect to theories of mind, metarepresentational theories seem to predict that theory of mind and pretend play would develop concurrently given that the same mechanism, the decoupler, underlies both. A standard problem for this view has been that the classic literature on the false-belief task runs afoul of this prediction. Whereas pretend play begins around 2 years old, children do not perform well on verbal tasks that require inferring the beliefs of others until around 4 years old. In recent years, however, the classic literature's claim has been challenged. Studies that infer children's understanding of false beliefs from their gaze patterns rather than from solicited verbal responses seem to suggest that children develop an understanding of false beliefs much earlier than previously thought. Some of this research suggests that capacity is already present in 15-month-olds, which is the time when make-believe play begins to be observed (see Refs 44 and 45; for a review, see Ref 46). At the time of writing, this issue remains unresolved.

Finally, turning to autism, metarepresentationalism provides a ready explanation for the cluster of deficits that typify autistic subjects. But simulationists like Harris ${ }^{2}$ and Currie and Ravenscroft ${ }^{4}$ have given alternative explanations of autistic children's simultaneous deficiencies in pretend play and theory of mind: they attribute simulational deficiency rather than metarepresentational deficiency to the children, thereby suggesting that the evidence from that domain does not tell unambiguously in favor of metarepresentationalism.

Intentionalist views attempt to strike a balance between metarepresentationalist views and behaviorist views. On such accounts, when people pretend they do not merely behave-as-if, they act-as-if. In recent psychological literature, Rakoczy et al. ${ }^{42}$ have been the main proponents of the intentionalist view (for an apparent early statement, see Searle, ${ }^{41}$ p. 65). On the one hand, intentionalists' notion of pretense is more mentalistic than behaviorists' because it includes intentionality as an essential component. On the other hand, this notion is less mentalistic than metarepresentationalists' because it does not require children to possess and deploy the concept PRETENSE in performing and recognizing pretense behaviors.

One of the key findings adduced in favor of the intentionalist view is that children as young as 2 to 3 years old can distinguish pretense actions from failed attempts at genuine actions on the basis of recognizing the intentions behind them. ${ }^{42}$ To understand this finding in context, we turn next to discussions about the recognition of pretense.

\section{RECOGNITION OF PRETENSE}

In contrast to issues related to the performance of pretense, comparatively less attention has been paid to the recognition of pretense, particularly by philosophers. Two central questions arise in this domain. First, how do people recognize one another as pretending? Second, how do people indicate to others that they are pretending? In this section, we review the developmental timeline, identify some of the indicators of pretense that aid recognitions, and explore implications of attending to this aspect of pretense.

\section{Developmental Timeline}

Alongside the capacity to perform pretense, the capacity to recognize pretense also develops significantly during a child's second year. As pretend play develops to take on features such as conventional representations and scripts, children's understanding of pretense deepens to include those additions.

Even children as young as 15 months show few signs of what Alan Leslie has termed 'representational abuse', that is, little indication of coming overtly to believe that actual-world objects have or will come to have features of the pretend objects that they serve to 
represent. ${ }^{7}$ Additional research suggests that children of this age already have some implicit understanding of the normativity of pretend games: they show evidence of comprehending that pretend games have their own sets of rules that one could conform to or violate. ${ }^{47}$

By 18 months, many show signs of tracking rather elaborate games of pretense initiated by others-for instance, being able to identify which of two dolls that have been 'washed' by an adult experimenter is 'still wet' and engaging in the requisite 'drying' activity. ${ }^{14}$ Children this age are also able to reliably tell, based on behavioral cues alone, whether a series of actions are genuine or merely pretend. ${ }^{48}$

By the age of 3 , children are able to articulate explicitly a number of the differences between real and pretend-noting, for instance, that a child with a real dog will be able to see and pet the dog, whereas a child with a pretend dog will not. ${ }^{2,49,50}$ They also show a tendency to actively protest when another participant violates the conventional norms of the pretend game. ${ }^{51-53}$ In the domain of imaginative engagement with fictions, children this age also begin to express skepticism about the factuality of fictions, indicating a capacity to separate fantasy from reality. ${ }^{54,55}$

Early childhood recognition of pretense appears to rely primarily on instinctive behavioral cues common to human and non-human pretend play (see section on Indicators of Pretense). Later on, children begin to recognize pretense on the basis of conventional features. When watching videotaped behavioral episodes, 4-year-olds show some difficulty in recognizing pretense behavior, whereas 7-year-olds recognize pretense behavior as reliably as adults, likely due to their recognition of stereotyped actions. ${ }^{56}$ In the domain of imaginative engagement with fictions, children between the ages of 3 and 5 begin to develop understandings of different genre norms, judging events in realistic (as opposed to fantasy) fictions as more likely to really happen. ${ }^{55}$

\section{Indicators of Pretense}

To recognize pretense, there must be indicators of pretense that are deployed that could be reliably tracked. The capacity to recognize and indicate pretense also exists in non-human animals. Special behavioral cues have been found to precede play fighting in rats, ${ }^{57}$ dogs, ${ }^{58}$ and other canids. ${ }^{59,60}$ Canids also adopt stereotyped, shorter-duration actions in play fighting, which they do not do in genuine fighting. ${ }^{61}$

In humans, behavioral cues of pretense range from instinctual to conventionalized. Perhaps surprisingly, explicit verbal cues are rarely used to indicate that an episode is 'only pretend'. ${ }^{48}$ Among the important features that have been found to correlate reliably with identification of pretense are the following:

\section{Gaze}

When mothers are only pretending to consume a snack and a drink, as opposed to genuinely doing so, they tend to gaze at children for longer durations. ${ }^{48}$ Direction and duration of gaze also plays a central role in allowing viewers of videoclips of these episodes to distinguish pretend from genuine behavior. ${ }^{56}$ It appears that even children as young as 18 months distinguish pretense from authentic behavior through differences in gaze. ${ }^{47}$

\section{Smile}

The research on smile as an indicator of pretense has produced mixed findings. Some researchers have suggested 'knowing' smiles after pretense behavior are strong indicators. ${ }^{11,62}$ But Richert and Lillard did not find correlations between patterns of smiles and identifications of pretense in their videoclips study. ${ }^{56}$ The mixed evidence may be due to the inherent difficulty in distinguishing the different kinds of smiles.

\section{Movement}

As noted earlier, non-human animals use stereotyped actions to indicate play fighting. Similar tendencies are found in humans. For example, when pretending to eat, one might exaggerate the chewing and do so more slowly (or quickly). These unusual repetitions and timings of movements are reliable indicators of pretense for older children and adults, ${ }^{56}$ but not for 18-month-olds. ${ }^{48}$

\section{Sound Effects}

Adults and older children both use sound effects to indicate pretense, ${ }^{63}$ for example, making 'vroom vroom' sounds when pretending that an object is a car. However, like other cues on the conventional end of the spectrum, sound effects are not used by 18 -montholds to recognize pretense. ${ }^{48}$ Children as young as 2 and 3 years also have the ability to recognize pretense from exaggerated speech patterns. ${ }^{64}$

\section{Implications}

The developmental timeline of pretense recognition and the range of pretense indicators have significant implications for the debate concerning the cognitive underpinnings of pretense. An adequate theory of pretense needs to explain both the performance aspect and the recognition aspect of pretense episodes. Evidence from recognition of pretense 
has thus been used to argue for the theories of pretense reviewed earlier (see section on Pretense and Mindreading/Theory of Mind).

On the one hand, metarepresentationalists can argue that their views are preferable on grounds of theoretical economy: such accounts can explain both performances of pretense and recognitions of pretense with the same theoretical resource: the concept PRETEND. In contrast, they claim, behaviorists-and intentionalists, who they consider to be a mere variant of behaviorists-require two distinct mechanisms for performing and recognizing pretense, with no clear explanation of the link between them. Metarepresentationalists also cite the existence of conventionalized indicators of pretense as evidence in their favor. Behaviorist views, they claim, have trouble explaining why the mother making a 'vroom vroom' sounds is a way to pretend a pencil is a car. After all, it is not the pencil that is behaving-as-if it were a car by making 'vroom vroom' sounds, nor is the mother pretending to be a car. Friedman and Leslie ${ }^{43}$ reviews arguments in favor of metarepresentationalist views.

On the other hand, behaviorists can cite the developmental timeline of pretense recognition capacities as evidence for the centrality of behavior to pretense. While children typically do not understand metarepresentations until 4 years old, they are typically able to recognize pretense on the basis of behavioral cues when they are as young as $2 .{ }^{38,65}$ Independently, behaviorists might argue that metarepresentationalist views sit uneasily with the ethological data. Unless one wants to maintain that animals such as rats possess the concept PRETEND, it is unclear how the metarepresentational view would explain recognitions of pretense in animal play fighting. Lillard ${ }^{17}$ reviews arguments in favor of behaviorist views.

Finally, intentionalists too can cite as evidence that children's understanding of the intentional structure of human behaviors develops around the same time as their capacity for recognizing pretense. As mentioned above, the experiments in Rakoczy et al. ${ }^{42}$ show that young children can distinguish pretense actions from failed attempts at genuine actions on the basis of their recognition of the intentions behind them.

Whereas philosophers have been active participants in the debate over the cognitive underpinnings of the performance aspect of pretense, the recognition aspect of pretense has been comparatively neglected in these discussions. Considering the close relations between them, much work remains to be done drawing out the philosophical import of the psychological findings of pretense recognition.

\section{IMAGINATIVE ENGAGEMENT WITH FICTIONS}

When we read books, watch movies, listen to stories, and participate in other aesthetic experiences, an important part of our engagement is imagining the content of the narratives. Indeed, Walton ${ }^{1}$ has argued that the same capacity that underlies children's make-believe games is also what allows us to have experiences of aesthetic appreciation, even of nonnarrative arts. Philosophers and psychologists have investigated how real-world beliefs, attitudes, and dispositions influence imaginative engagement with fictions, but largely in isolation. In this section, we attempt to bring together two such bodies of work: philosophical work on imaginative resistance and psychological work on transportation.

\section{Imaginative Resistance ${ }^{b}$}

In considering the capacities that underlie imaginative engagements with fictions, philosophers in recent years have devoted a good deal of attention to the puzzle of imaginative resistance. The phenomenon, imaginative resistance, occurs when a subject finds it difficult or problematic to engage in some sort of prompted imaginative activity. Suppose, for example, that you were confronted with a variation of Macbeth where 'the facts of [Duncan's] murder remain as they are in fact presented in the play, but it is prescribed in this alternate fiction that this was unfortunate only for having interfered with Macbeth's sleep'. ${ }^{66}$ If you found it difficult to imagine this, even though the author had done everything that usually done to make such a story fictionally true, then you would be experiencing imaginative resistance.

While early discussions of imaginative resistance, such as Walton ${ }^{67}$, tended to focus on examples (like the one above) involving 'morally deviant' worlds, it is now widely agreed that this initial characterization was too restrictive (for partial dissent, see Gendler $\left.{ }^{68}\right)$. In more recent literature, the term is typically applied to any sort of case where subjects find it unexpectedly difficult to (bring themselves to) imagine what an author describes, or to accept such a claim as being true in the story. So, for example, Weatherson ${ }^{69}$ has argued that resistance puzzles arise not only for normative concepts (including thick and thin moral concepts, aesthetic judgments, and epistemic evaluations), but also for attributions of mental states, attributions of content, and even claims involving constitution or ontological status.

As Walton ${ }^{70}$ notes, the questions addressed under the rubric of imaginative resistance turn out to be a 'tangled nest of importantly distinct but 
easily confused puzzles'. Indeed, Weatherson ${ }^{69}$ has argued that there are at least four such puzzles. The phenomenological puzzle is the puzzle of why certain passages tend to evoke a particular phenomenology, sometimes described as 'pop-out'or 'doubling of the narrator'. ${ }^{68,71}$ The imaginability puzzle is the puzzle of why, in certain cases, readers display a reluctance or inability to engage in some mandated act of imagining, so that typical invitations to make-believe are insufficient. The fictionality puzzle is the puzzle of why, in certain cases, the default position of authorial authority breaks down, so that mere authorial say-so is insufficient to make it the case that something is true in a story. And in its most general form, the aesthetic value puzzle is the puzzle of why, in certain cases, texts that evoke other sorts of imaginative resistance are thereby aesthetically compromised.

In the discussion below, we will concentrate on the phenomenology and the imaginability puzzles, as they are most closely tied to the psychology of participating in make-believe with fictions (see section on Exploring Connections below.)

\section{Transportation}

A number of psychologists interested in the capacities that underlie imaginative engagement with fiction have explored the phenomenon through the concept of transportation. To be transported is, roughly, to feel immersed in a fictional world, so much so that the real world temporarily ceases to feel accessible. One might think of it as the opposite of imaginative resistance. A similar feeling of transportation may arise in episodes of pretense (Velleman ${ }^{72}$ and Doggett and Egan $^{6}$ discuss the feeling of being immersed in pretense).

Transportation theory has its origins in Gerrig, ${ }^{73}$ and is elucidated in detail in Green and Brock. ${ }^{74}$ On their account, transportation is 'a distinct mental process, an integrative melding of attention, imagery, and feelings' ${ }^{74}$ To be transported, readers must let their imaginings be phenomenologically dominant, trigger mental imagery, and cause emotional responses. In the scale that Green and Brock have developed to measure the extent to which readers are transported, all three components—cognitive, affective, and imagery-are measured. While their initial experiments focused on short, written narratives, Green and Brock ${ }^{74}$ make it clear that transportation theory is intended to apply across engagements with fictions of different forms. Later works by Dal Cin et al. ${ }^{75}$ and Rowe Stitt and $\mathrm{Nabi}^{76}$ take up this task and extend the theory to cases of film.

Psychologists have identified a number of factors that influence the extent to which an appreciator is transported. Generally speaking, consistency between an appreciator's prior belief and what is true in the fiction positively correlates with greater transportation into those fictional worlds, ${ }^{77}$ whereas stories in which real-world associations are violated tend to produce initial transportational difficulties. ${ }^{78}$ There are also individual differences among subjects, with individuals showing greater or lesser tendencies to become immersed in a wide range of circumstances; these differences can be measured using Dal Cin et al.'s ${ }^{75}$ transportability scale. There is also preliminary evidence suggesting that genre familiarity could be another important factor in affecting transportation among subjects, particularly those with relatively high transportability ${ }^{79}$

\section{Exploring Connections}

Although a number of recent discussions of resistancerelated phenomena draw on related work in cognitive and social psychology,, $80-82$ work on transportation has largely been ignored. One way to connect the two phenomena, as suggested earlier, is to see imaginative resistance as an extreme case of being not transported at all. If so, there may be useful connections to be drawn between the two bodies of work. The cognitive component of the transportability scale contains items such as 'While I was reading the narrative, I could easily picture the events in it taking place'. ${ }^{74}$ Although Green and Brock do not use the same terms as the philosophers, they appear to be interested in the comparative ease to which the consumer of the narrative could imagine the events taking place. In addition to the cognitive component, transportation also includes affective and imagery components. In contrast, the discussion of imaginative resistance appears to place relatively little emphasis on these aspects of people's experiences when imaginative engaging with narratives. Diving deeper into these aspects of imaginative resistance might enrich philosophers' discussion of the phenomenon.

On the other hand, psychologists could also deepen their understanding of transportation by borrowing a distinction from philosophers. The psychologists who have studied transportation theory have focused largely on the impact that beliefs, attitudes, and dispositions have on imagining certain descriptive propositions. Philosophers, on the other hand, have focused attention on fictional normative claims, such as that female infanticide is justified, because of the problems they pose for imaginative engagement with fictions. Given this important distinction made in philosophy, it seems worthwhile for psychologists to gather empirical results on how 
people respond to moral and other normative claims in fiction, which may differ from their responses to descriptive claims.

\section{THE REAL-WORLD IMPACT OF MAKE-BELIEVE}

Having briefly reviewed how real-world beliefs, attitudes, and dispositions impact make-believe, we will now consider the reverse: the real-world impact of pretense and imaginative engagement with fictions. As before, philosophers, psychologists, and researchers in allied fields have longstanding interest in this topic, but have worked largely in isolation. In this section, we attempt to bring together the research on fiction's role in moral education and on the effects that fictions have on beliefs, attitudes, and dispositions.

\section{Fiction's Role in Moral Education}

Since ancient times, philosophers and others have argued that fiction can play a role in the moral education of those who imaginatively engage with it, that is, in the development of their abilities to think and act in morally desirable ways.

On the surface, this claim faces obvious epistemological worries. Carroll ${ }^{84}$ summarizes three lines of purported arguments against aesthetic cognitivism - the view that we can gain knowledge from imaginatively engaging with fictions. The banality argument charges that even if we could gain knowledge from fictions, the scope would be limited to truths that are banal or already known. The no-evidence argument objects that artworks are unsuitable evidence for drawing general inferences. The no-argument argument points out that fictions, by their very nature, do not provide arguments or justifications for the claims they assert.

To circumvent worries posed by these arguments, Carroll, ${ }^{84}$ Currie, ${ }^{85}$ Jacobson, ${ }^{86}$ Johnson, ${ }^{87}$ Mullin, ${ }^{88}$ Nussbaum, ${ }^{89}$ and Robinson ${ }^{90}$ have proposed various subtly different versions of aesthetic cognitivism that focuses less on beliefs and more on emotions and implicit attitudes. They suggest that fictions can play a role in moral education by allowing imaginative acquaintance with unfamiliar moral perspectives and emotions, and cultivate existing moral understanding and capabilities by creating and directing the reader's attention to novel situations to which that understanding can be applied.

For Nussbaum, to take one example, an important skill in the moral domain is the ability to discern morally salient features of one's situation. This skill, she argues, is the one that must be developed, and one to which the engagement with literature might effectively contribute by providing 'close and careful interpretative descriptions' of imagined scenarios that enable emotional involvement untainted by distorting self-interest. ${ }^{89}$ Hakemulder ${ }^{91}$ reviews some psychological evidence for this hypothesis.

\section{Effects of Fictions on Beliefs, Attitudes, and Dispositions}

Although psychologists and researchers from communication and media studies have not specifically focused on the dimension of morality, they have investigated the effects that imaginatively engaging with fictional narratives have on people's beliefs, attitudes, and dispositions (for a broad review, see Brock et al. $\left.{ }^{92}\right)$.

In considering the effects that narratives have on one's beliefs, let us start with an example before discussing the mechanisms that underly these effects and the scope of these effects. In a study reported in Green, ${ }^{77}$ participants read Lynn Harris's short story 'Just as I am' that describes, from a firstperson perspective, a gay man's experience returning to his old fraternity for a reunion and encountering homophobia. After reading the story, participants responded, among others, to statements that relate to homophobia in fraternities. Participants who reported being more transported into the fiction also showed a tendency to agree more strongly with claims about the real world that are consistent with the story, such as 'people in fraternities are homophobic', even when prior attitudes and experiences were controlled for.

Likewise, Prentice et al. ${ }^{93}$ found that participants who read factually-false statements in the context of a fictional narrative-statements such as 'sunlight is good for your skin' and 'most forms of mental illness are contagious'-are more inclined to believe them to be true in the real world. Other research suggests that the same narrative can influence readers' beliefs as much when it is labeled as a fictional television drama script as when it is labeled as news broadcast transcript ${ }^{94}$ (see also Marsh et al..$^{95}$ for similar findings).

What mechanisms could explain how fictions, even when recognized as such, influence our beliefs about the real world? One factor is the effect of mere exposure to information. Existing findings show that people's default psychological toward information is belief, and that it takes additional effort to 'unbelieve' information that has been processed. ${ }^{96,97}$ As such, exposure to content, even in an explicitly fictional context, may strengthen one's beliefs about it, ${ }^{74,77,93}$ perhaps because when imaginatively engaging with 
fictions, people tend not to engage in critical processing of the information presented, showing indifference to its source. ${ }^{74,95}$

More empirical evidence is needed to specify the scope of the influence that fictions have on people's beliefs about the real world. Fictions might only be able to exert influence people's beliefs when people are not attentive to this possibility. Shrum et al. ${ }^{98}$ found that participants who were primed to think of television as a possible influence on their beliefs about the prevalence of crime and of certain occupations experienced less change to their beliefs compared with participants who were not so primed. Explicit warnings may also encourage critical processing of information in fictions. Pechmann and Shih ${ }^{99}$ found that while positive depictions of smoking in films tend to increase youth's intent to smoke, this effect is nullified by an explicit anti-smoking message appearing before a film.

Although these studies begin to map out the scope of fiction's influence, other questions remain open. First, which fictions can influence people's beliefs about the real world? Clearly, people would not believe in the existence of dragons even after being exposed to such information in a fantasy story. Given that all the stories that have been used as stimuli tend to be realistic fictions, more research is needed on the effect of different genres. (For preliminary work in this area, see Ref 79.) Second, which beliefs are more prone to be influenced by information presented in fictions? Given that all the statements that experiment participants have been asked to respond to are descriptive, one naturally wonders (especially given the phenomenon of imaginative resistance discussed earlier), whether the results generalize to evaluative statements (see section on Exploring Connections below.)

The precise extent to which fictions influence people's attitudes and dispositions is also controversial. One area where considerable attention has been devoted to is the effect of exposure to imaginary violence. Earlier studies claiming that exposure to violence in media results in an overall distrustful attitude toward the real world (e.g., Gerbner et al. ${ }^{100}$ ) has been criticized on methodological grounds. ${ }^{101}$ Recent evidence suggests that fictions do influence attitudes and dispositions, albeit in limited ways. For example, Williams ${ }^{102}$ found that when participants are exposed to armed robbery in a video game, their assessment of the likelihood of armed robbery occurring in the real world increases; however, their attitudes toward other violent crimes, such as physical assault, rape, and murder remain unchanged. This suggests that attitudinal and dispositional changes brought on by imaginatively engaging with fictions may be circumscribed.

\section{Exploring Connections}

In thinking about the implications of the empirical research on the effects of fictions on beliefs, attitudes, and dispositions for philosophical theorizing, it may be helpful to think about its consequences for various versions of aesthetic cognitivism-the view that we can gain knowledge from imaginatively engaging with fictions. Contemporary philosophers who work on explaining how fictions may play a role in moral education (discussed earlier in section on Fiction's Role in Moral Education), such as Martha Nussbaum, have tried to sidestep traditional epistemological worries with aesthetic cognitivism by focusing on fictions' influences on attitudes and dispositions rather than their influences on beliefs. Consider Nussbaum's proposal that fiction's contribution to moral education is that it allows us to examine imagined scenarios without distortions of self-interest, and thus improve on our skills of discerning morally salient features of a situation. An assumption appears to be that practice noticing morally salient features in particular fictional situation can indeed improve one's ability to notice morally salient features generally in real-world situations. However, this assumption called into question by the empirical findings suggesting that attitudinal and dispositional changes brought on by imaginatively engaging with fictions may not generalize well from the specific fictional situations encountered. Further empirical investigation is warranted.

At the same time, psychology and allied fields could benefit from interactions with the rich philosophical literature on moral education. Few studies concerning the impact of fiction have focused explicitly on moral (as opposed to descriptive or merely social-conventional) beliefs, attitudes, and dispositions. Looking into the moral and otherwise evaluative aspects of fictions could help clarify the scope of fiction's influence, as well as potentially informing us about the underpinnings of moral psychology.

\section{OTHER ROLES FOR THE IMAGINATION ${ }^{c}$}

Thus far, we have focused on a number of paradigmatic roles of the imagination, in particular, its roles in allowing us to participate in pretense and engage with fictions and other representational arts. However, the imagination may also be implicated in other facets of our mental lives: in counterfactual reasoning, delusions, and dreaming. Attending to philosophical and psychological research in these areas allows us to better understand the fundamental 
nature of the imagination and its role in the human cognitive architecture, and consequently gives us a more complete picture of its involvement in pretense.

\section{Counterfactual Reasoning}

Pre-theoretically, people tend to think of imagination as free-flowing and without guidance-the opposite of 'rational thinking'. Considering imagination's role in evaluating counterfactuals, however, demonstrates that constrained imagination plays a central role in everyday reasoning about possibilities.

Timothy Williamson, for example, suggests that 'When we work out what would have happened if such-and-such had been the case, we frequently cannot do it without imagining such-and-such to be the case and letting things run' (Williamson, ${ }^{103}$ p. 19; cf. Williamson ${ }^{104}$ ). On this sort of account, if Juliet thinks to herself, 'If only the messenger had reached him with the news, Romeo would still be alive', it is Juliet's imagining a relevant situation in which Romeo does not believe that she is actually dead that allows her to move from the antecedent to the consequent of the counterfactual conditional that she entertains. Clearly, such contemplation gives access to a suitably circumscribed set of worlds only if the imaginative exercise is somehow constrained with respect to what is held constant.

In considering how to apply truth-valuation to counterfactual conditionals, philosophers have implicitly given guidelines on how imagination ought to be constrained in counterfactual reasoning. On the classic account of counterfactual conditionals developed by Stalnaker ${ }^{105}$ and Lewis, ${ }^{106,107}$ a counterfactual $\mathrm{A}[] \rightarrow \mathrm{C}$ is true if and only if in the closest possible world where $\mathrm{A}$ is true and $\mathrm{C}$ is also true. (One difference between them is that while Stalnaker assumes that there is always a unique closest world in a given context, Lewis does not.) Accordingly, when we imagine in aid of counterfactual reasoning, our imaginings should be constrained to possible worlds that minimize departures from reality. A great deal of philosophical discussion has been devoted to specifying what these constraints amount to. (For reviews of some of these issues, see section 5 of Edgington ${ }^{108}$ and section 6 of Arlo-Costa. ${ }^{109}$ )

The question of what tends to be held constant when subjects contemplate counterfactual scenarios has been explored in detail in recent empirical psychological work. (Cf. Johnson-Laird ${ }^{110}$ and essays collected in Roese and Olson. ${ }^{111}$ ) In her monographlength discussion of the role of imagination in counterfactual reasoning, Ruth Byrne ${ }^{112}$ presents evidence showing that when people reason using counterfactuals, their imaginings tend to follows certain patterns which she calls 'faultlines in reality'. For example, people tend not to imagine worlds with different natural laws, and they tend to imagine alternatives to more recent as opposed to earlier events, alternatives to actions as opposed to inactions, and alternatives to events that were within their control as opposed to events outside of it. Clearly, some of the 'faultlines' that Byrne proposes share strong affinities with constraints that philosophers like Lewis and Stalnaker have proposed. These 'faultlines' are also evident in what people include in the construction of fictional worlds. ${ }^{113}$ However, Rafetseder et al. ${ }^{114}$ present evidence that suggest children up to 6 years old do not consistently employ the nearest-possibleworld model in counterfactual reasoning. (For an overview of additional work in psychology in this area, see section III of the survey in Markman et al. ${ }^{115}$ )

\section{Delusions}

Delusions can be characterized, roughly, as belieflike mental representations that manifest an unusual degree of disconnectedness from reality. Delusions are problematic to categorize because they seem to exhibit features of both belief and imagination. One striking example of a delusion is Capgras syndrome, where the sufferer takes her friends and family to have been replaced by imposters. As Egan ${ }^{116}$ points out, while a person who suffers from Capgras delusion might act differently toward their friends and family as a result (the delusion thus can motivate like belief), she might not draw all the inferences on her overall worldview that her delusional thoughts demand (the delusion thus is circumscribed like imagination). Given its imagination-like features, attending to delusions give us a different insight into the role that imagination and pretense play in our cognitive architecture.

A natural way to characterize delusions is as beliefs that are in some way dysfunctional or, alternatively, as beliefs that are formed in a dysfunctional way. (For a representative collection of papers that present and criticize this perspective, see Coltheart and Davies ${ }^{117}$ ). Currie and Ravenscroft, ${ }^{4}$ however, have argued that delusions are often disorders of the imagination (pp. 170-175). On their account, delusions should be understood as involving a deficit in the subject's ability to distinguish between what is imagined and what is believed. Relating back to theories of pretense, delusions appear to involve a deficit in the capacity to recognize pretense as such.

Other philosophers take delusions to present difficulties for a clear-cut theoretical divide between belief and imagination. On Gendler's account, ${ }^{118,119}$ 
delusions may occur when imaginings come to play the role of belief in one's cognitive economy. On Andy Egan's account, ${ }^{116}$ delusions should be understood as 'bimaginations', that is, as something in between beliefs and imaginings.

\section{Dreaming}

As is the case with delusions, it is difficult to categorize the mental states involved in dreams. Whether dreaming involves imagining or believing has wider philosophical implications. In epistemology, Descartes famously used the fact that we often dream without recognizing it to motivate an argument for external-world skepticism. An implicit premise in the Cartesian skeptic's argument is that dreaming involves beliefs that indistinguishable from normal beliefs about the external world.

More recently, however, philosophers and psychologists have appealed to imagination to characterize dreaming. For example, philosopher Walton ${ }^{1}$ describes dreams as 'spontaneous, undeliberate imaginings', and psychologist David Foulkes characterizes dreaming as 'the awareness of being in an imagined world in which things happen' (p. 9). ${ }^{120}$ By considering the differences between the dream mental states and normal beliefs, such as their relations to perceptual experience and actions, Ichikawa ${ }^{121}$ contends that the mental states involved in dreams are not beliefs, but imaginings. The epistemological implications of characterizing dreaming by appealing to imagination have been a source of dispute. Sosa ${ }^{122,123}$ claims and Ichikawa $^{121}$ denies that this reconstrual fully blunts the force of the Cartesian dreaming argument.

However, as John Sutton's survey article on dreaming ${ }^{124}$ points out, the topic of dreaming has been relatively neglected in philosophy of mind in general, including the literature on imagination. One exception is the book-length treatment in Flanagan ${ }^{125}$ that examines the nature and function of dreams. Given its interest for imagination's role in our cognitive architecture and wider philosophical implications, the topic of dreaming merits further theoretical and empirical investigation.

\section{CONCLUSION}

Numerous points of connection exist between philosophical and psychological work on pretense, some relatively well-explored, others in need of further investigation. In this entry, we have identified some of the areas on which the research programs do or could overlap, including performing and recognizing pretense (see sections on The Cognitive Underpinnings of Pretense and Recognition of Pretense), imaginative engagement with fiction (see section on Imaginative Engagement with Fictions), the real-world impact of make-believe (see section on The Real-World Impact of Make-Believe), and counterfactual reasoning, delusions, and dreaming (see section on Other Roles for the Imagination).

Along the way, we have made suggestions on future research, especially where greater interdisciplinary interactions can be fruitful. Let us briefly recap these suggestions:

- Increasingly, debates between theories of pretense turn on their ability to account for children's recognition of pretense. Although philosophers have been actively involved in the research on the performance aspect of pretense, the recognition aspect of pretense has been comparatively neglected. Much work remains on drawing out the philosophical import of the psychological findings of pretense recognition.

- In discussions of imaginative resistance, philosophers have focused primarily on difficulties with propositional imagination. Drawing a parallel between philosophical research on imaginative resistance and psychological research on transportation, however, reveals that philosophers' discussions can be enriched by attending to the affective and imagery aspects of people's experiences.

- Theories of moral education implicitly make commitments regarding how imaginatively engaging with fictions can influence people's morally relevant beliefs, attitudes, and dispositions. On the theoretical side, philosophers can do more in making explicit the psychological commitments of various theories. On the empirical side, findings about the mechanisms and the scope of fictions' impact on people can contribute to assessing the plausibility of theories, once their psychological commitments are made explicit.

- Psychological research on transportation and fictions' impact on people have focused primarily on realistic fictions and on descriptive propositions. Philosophical research on imaginative resistance and moral education, however, suggests that existing psychological findings may not generalize to fictions of other genres and to evaluative propositions. A diverse range of stimuli could help researchers gain an even richer understanding of these phenomena. 
- Research on counterfactual reasoning reveals interesting patterns of imaginings that people tend to employ. Recent results suggest that the same patterns are also evident in the construction of make-believe worlds. A better understanding of imagination's involvement in pretend play and engagement with fictions may result from attending to imagination's involvement in counterfactual reasoning.

- Delusions and dreams provide interesting challenges to understanding the nature of imagination and its place in cognitive architecture.
The involvement of imagination in dreaming has been especially neglected. Responding to these challenges can further our understanding of the capacities that underwrite pretend play and engagement with fictions.

\section{NOTES}

${ }^{a}$ Discussion in this section draws on Gendler. ${ }^{126,127}$

${ }^{b}$ Discussion in this section draws on Gendler. ${ }^{128}$

${ }^{c}$ This section draws on Gendler. ${ }^{126}$

\section{ACKNOWLEDGEMENTS}

We thank Shaun Nichols and an anonymous referee for suggestions that improved the organization and comprehensiveness of this review. We also thank Aaron Norby, Daniela Tagliafico, and Deena Skolnick Weisberg for their bibliographical advice.

\section{REFERENCES}

1. Walton K. Mimesis as Make-Believe. Cambridge, MA: Harvard University Press; 1990.

2. Harris PL. The Work of the Imagination. Oxford: Blackwell; 2000.

3. Nichols S, Stich S. Mindreading: An Integrated Account of Pretense, Self-awareness and Understanding Other Minds. Oxford: Oxford University Press; 2003.

4. Currie G, Ravenscroft I. Recreative Minds: Imagination in Philosophy and Psychology. Oxford: Oxford University Press; 2002.

5. Strawson PF. Imagination and perception. In: Foster L, Swanson JW, eds. Experience and Theory. Amherst, MA: University of Massachusetts Press; 1970, 31-54.

6. Doggett T, Egan A. Wanting things you don't want: the case for an imaginative analogue of desire. Philos Imprint 2007, 7:1-17.

7. Leslie A. Pretense and representation: the origins of 'theory of mind'. Psychol Rev 1987, 94:412-426.

8. Nichols S. Imagining and believing: the promise of a single code. J Aesthet Art Crit 2004, 62:129-139.

9. Fodor J. A theory of the child's theory of mind. Cognition 1992, 44:283-296.

10. Ryle G. The Concept of Mind. Chicago: University of Chicago Press; 1949.

11. Piaget J. Play, Dreams, and Imitation in Childhood. Gattegno C, Hodgson FM (trans.), New York: Norton; 1945/1962.
12. Harris PL, Kavanaugh RD. Young children's understanding of pretense. Monogr Soc Res Child Dev 1993, 58:Serial No. 231.

13. Harris PL. Understanding pretense. In: Lewis C, Mitchell P, eds. Children's Early Understanding of Mind. Hillsdale, NJ: Lawrence Erlbaum; 1994, 235-259.

14. Walker-Andrews AS, Kahana-Kelman R. The understanding of pretense across the second year of life. $\mathrm{Br}$ J Dev Psychol 1997, 17:523-536.

15. Perner J, Baker S, Hutton D. Prelief: the conceptual origins of belief and pretense. In: Lewis C, Mitchell P, eds. Children's Early Understanding of Mind. Hillsdale, NJ: Lawrence Erlbaum; 1994, 261-286.

16. Goldman A. Simulating Minds. Oxford: Oxford University Press; 2006.

17. Lillard AS. Pretend play as twin earth: a socialcognitive analysis. Dev Rev 2001, 21:495-531.

18. Carruthers P. How we know our own minds: the relationship between mindreading and metacognition. Behav Brain Sci 2009, 32:121-138.

19. Baron-Cohen S, Leslie A, Frith U. Does the Autistic child have a 'theory of mind'? Cognition 1985, 21:37-46.

20. Happé F. Autism: An Introduction to Psychological Theory. London: UCL Press; 1994. 
21. Wing L, Gould J. Severe impairments of social interaction and associated abnormalities in children: epidemiology and classification. J Autism Dev Disord 1979, 9:11-29.

22. Carruthers P, Smith PK, eds. Theories of Theories of Mind. Cambridge: Cambridge University Press; 1996.

23. Davies M, Stone T, eds. Folk Psychology: The Theory of Mind Debate. Oxford: Basil Blackwell; 1995.

24. Davies M, Stone T, eds. Mental Simulation. Oxford: Basil Blackwell; 1995.

25. Lewis D. Psychophysical and theoretical identifications. Australas J Philos 1972, 50:249-258.

26. Wellman HM. The Child's Theory of Mind. Cambridge: MA, MIT Press; 1990.

27. Gopnik A, Wellman HM. Why the child's theory of mind really is a theory. Mind Lang 1992, $7: 145-171$.

28. Ravenscroft I. Folk psychology as a theory. In Zalta E, ed. The Stanford Encyclopedia of Philosophy (Fall 2004 Edition), 2004. Available at: http://plato.stanford.edu/entries/folkpsych-theory/.

29. Goldman A. Interpretation psychologized. Mind Lang 1989, 4:161-185.

30. Gordon R. Folk psychology as simulation. Mind Lang 1986, 1:158-171.

31. Heal J. Replication and functionalism. In: Butterfield J, ed. Language, Mind, and Logic. Cambridge: Cambridge University Press; 1986.

32. Gallagher S. Simulation trouble. Soc Neurosci 2007, 2:353-365.

33. Saxe R. Against simulation: the argument from error. Trends Cogn Sci 2005, 9:174-179.

34. Saxe R. The neural evidence for simulation is weaker than I think you think it is. Philos Stud 2009, 144:447-456.

35. Gordon R. Folk psychology as mental simulation. In: Zalta E, ed. The Stanford Encyclopedia of Philosophy (Fall 2009 Edition), 2009. Available at: http://plato.stanford.edu/entries/folkpsych-simula tion/.

36. Carruthers P. Review of recreative minds, by G. Currie and I. Ravenscroft. Notre Dame Philos Rev 11/12: 2003. Available at: http://ndpr.nd.edu/ review.cfm?id=1309.

37. Leslie A. Pretending and believing: issues in the theory of ToMM. Cognition 1994, 50:211-238.

38. Jarrold C, Carruthers P, Smith PK, Boucher J. Pretend play: is it metarepresentational? Mind Lang 1994, 9:445-468.

39. Lillard AS, Flavell JH. Young children's understanding of different mental states. Dev Psychol 1992, 28:626-634.
40. Perner J. Understanding the Representational Mind. Cambridge: MIT Press; 1991.

41. Searle JR. Expression and Meaning: Studies in the Theory of Speech Acts. Cambridge: Cambridge University Press; 1979.

42. Rakoczy H, Tomasello M, Striano T. Young children know that trying is not pretending: a test of the 'behaving-as-if' construal of children's understanding of pretense. Dev Psychol 2004, 40:388-399.

43. Friedman O, Leslie A. The conceptual underpinnings of pretense: pretending is not 'behaving-as-if'. Cognition 2007, 105:103-124.

44. Onishi KH, Baillargeon R. Do 15-month-old infants understand false beliefs? Science 2005, 308:255-258.

45. Southgate V, Senju A, Csibra G. Action anticipation through attribution of false belief by 2 -year-olds. Psychol Sci 2007, 18:587-592.

46. Baillargeon R, Scott R, He Z. False-belief undertanding in infants. Trends Cogn Sci 2010, 14:110-118.

47. Onishi KH, Baillargeon R, Leslie AM. 15-Month-old infants detect violations in pretend scenarios. Acta Psychol 2007, 124:106-128.

48. Lillard AS, Witherington DS. Mothers' behavior modifications during pretense snacks and their possible signal value for toddlers. Dev Psychol 2004, 40:95-113.

49. Bouldin P, Pratt C. The ability of children with imaginary companions to differentiate between fantasy and reality. Br J Dev Psychol 2001, 19:99-114.

50. Estes D, Wellman H, Wooley J. Children's understanding of mental phenomena. In: Reese HW, ed. Advances in Child Development and Behavior. Vol. 22. San Diego: Academic Press; 1989, 41-87.

51. Golomb C, Kuersten R. On the transition from pretense play to reality: what are the rules of the game? Br J Develop Psychol 1996, 14:203-217.

52. Rakoczy H. Taking fiction seriously: young children understand the normative structure of joint pretend games. Dev Psychol 2008, 44:1195-1201.

53. Wyman E, Rakoczy H, Tomasello M. Normativity and context in young children's pretend play. Cogn Dev 2009, 24:146-155.

54. Skolnick D, Bloom P. The intuitive cosmology of fictional worlds. In: Nichols S, ed. The Architecture of the Imagination: New Essays on Pretense, Possibility, and Fiction. Oxford: Oxford University Press; 2006, $73-86$.

55. Woolley JD, Cox V. Development of beliefs about storybook reality. Dev Sci 2007, 10:681-693.

56. Richert R, Lillard AS. Observers' proficiency at identifying pretend acts based on different behavioral cues. Cogn Dev 2004, 19:223-240. 
57. Knutson B, Burgdorf J, Panksepp J. Anticipation of play elicits high-frequency ultrasonic vocalizations in young rats. J Comp Psychol 1998, 112:65-73.

58. Beckoff M. Social Play in Coyotes, Wolves, and Dogs. BioScience 1974, 24:225-230.

59. Bekoff M. Social communication in canids: evidence for the evolution of a stereotyped mammalian display. Science 1977, 197:1097-1099.

60. Bekoff M, Allen C. Intentional communication and social play: how and why animals negotiate and agree to play. In: Bekoff M, Byers JA, eds. Animal Play: Evolutionary, Comparative, and Ecological Perspectives. Cambridge: Cambridge University Press; 1998, 97-114.

61. Hill HL, Bekoff M. The variability of some motor components of social play and agonistic behaviour in infant eastern coyotes Canis latrans var. Anim Behav 1977, 25:907-909.

62. Wellman HM, Hickling AK. Understanding pretense as pretense. Monogr Soc Res Child Dev 1993, 58:93-102.

63. DeLoache JS, Plaetzer B. Tea for two: joint mother-child symbolic play. Paper presented at the biennial meeting of the Society for Research in Child Development, Toronto, Ontario, Canada, 1985.

64. Friedman O, Neary K, Burnstein C, Leslie A. Is young children's recognition of pretense metarepresentational or merely behavioral? Evidence from 2and 3-year-olds' understanding of pretend sounds and speech. Cognition 2010, doi: 10.1016/j.cogni tion.2010.02.001.

65. Lillard AS. Young children's conceptualization of pretense: action or mental representational state? Child Dev 1993, 64:372-386.

66. Moran R. The expression of feeling in imagination. Philos Rev 1994, 103:75-106.

67. Walton K. Morals in fiction and fictional morality. Proc Aristotelian Soc 1994, 68:27-50.

68. Gendler TS. Imaginative resistance revisited. In: Nichols S, ed. The Architecture of the Imagination: New Essays on Pretense, Possibility, and Fiction. Oxford: Oxford University Press; 2006, 149-173.

69. Weatherson B. Morality, fiction, and possibility. Philos Imprint 2004, 4:1-27.

70. Walton K. On the (so-called) puzzle of imaginative resistance. In: Nichols S, ed. The Architecture of the Imagination: New Essays on Pretense, Possibility, and Fiction. Oxford: Oxford University Press; 2006, 137-148.

71. Gendler TS. The puzzle of imaginative resistance. J Philos 2000, 97:55-81.

72. Velleman D. The aim of belief. In: The Possibility of Practical Reason. Oxford: Oxford University Press; 2000.
73. Gerrig R. Experiencing Narrative Worlds: On the Psychological Activities of Reading. New Haven, CT: Yale University Press; 1993.

74. Green MC, Brock TC. The role of transportation in the persuasiveness of public narrative. 2000, J Pers Soc Psychol 79:701-721.

75. Dal Cin S, Zanna MP, Fong GT. Narrative persuasion and overcoming resistance. In: Knowles ES, Linn JA, eds. Resistance and Persuasion. Mahwah, NJ: Erlbaum; 2004, 175-191.

76. Rowe Stitt C, Nabi RL. The persuasive impact of narratives: a comparison across message types and modalities. Paper presented at the Annual Conference of the International Communication Association in New York, 2005.

77. Green MC. Transportation into narrative worlds: the role of prior knowledge and perceived realism. Discourse Process 2004, 38:247-266.

78. Carreiras M, Garnham A, Oakhill J, Cain K. The use of stereotypical gender information in constructing a mental model: evidence from English and Spanish. Q J Exp Psychol 1996, 49A:639-663.

79. Bilandzic H, Busselle RW. Transportation and transportability in the cultivation of genreconsistent attitudes and estimates. J Commun 2008, 58:508-529.

80. Driver J. Imaginative resistance and psychological necessity. Soc Philos Policy 2008, 25:301-313.

81. Levy N. Imaginative resistance and the moral/ conventional distinction. Philos Psychol 2005, 18:231-241.

82. Weinberg J, Meskin A. Puzzling over the imagination: philosophical problems, architectural solutions. In: Nichols S, ed. The Architecture of the Imagination: New Essays on Pretense, Possibility, and Fiction. Oxford: Oxford University Press; 2006.

83. Weinberg JM. Configuring the cognitive imagination. In: Stock K, Thomsen-Jones, K, eds. New Waves in Aesthetics. New York: Palgrave Macmillan; 2008, 203-223.

84. Carroll N. The wheel of virtue: art, narrative and moral knowledge. J Aesthet Art Crit 2002, 60:3-26.

85. Currie G. The moral psychology of fiction. Australas J Philos 1995, 73:250-259.

86. Jacobson D. Sir Philip Sydney's Dilemma: on the ethical function of narrative art. J Aesthet Art Crit 1996, 54:327-336.

87. Johnson M. Moral Imagination: Implications of Cognitive Science for Ethics. Chicago: University of Chicago Press; 1994.

88. Mullin A. Moral defects, aesthetic defects, and the imagination. J Aesthet Art Crit 2004, 62:249-261.

89. Nussbaum M. Love's Knowledge. Oxford: Oxford University Press; 1990. 
90. Robinson J. Deeper than Reason: Emotion and its Role in Literature, Music, and Art. New York: Oxford University Press; 2005.

91. Hakemulder FJ. The Moral Laboratory: Experiments Examining the Effects of Reading Literature on Social Perception and Moral Self-Knowledge. Amsterdam: Benjamins; 2000.

92. Brock TC, Strange JJ, Green MC. Power beyond reckoning: an introduction to narrative impact. In: Green MC, Strange JJ, Brock TC, eds. Narrative Impact: Social and Cognitive Foundations. Mahwah, NJ: Lawrence Erlbaum Associates, Inc.; 2002, 1-16.

93. Prentice DA, Gerrig RJ, Bailis DS. What readers bring to the processing of fictional texts. Psychon Bull Rev 1997, 5:416-420.

94. Green MC, Garst J, Brock TC, Chung S. Fact versus fiction labeling: persuasion parity despite heightened scrutiny of fact. Media Psychol 2006, 8:267-285.

95. Marsh EJ, Meade ML, Roediger HL III. Learning facts from fiction. J Mem Lang 2003, 49:519-536.

96. Bernstein DM, Godfrey RD, Loftus EF. False memories: the role of plausibility and autobiographical belief. In: Markman KD, Klein WMP, Suhr JA, eds. Handbook of Imagination and Mental Simulation. New York: Taylor \& Francis; 2009, 89-102.

97. Gilbert D. How Mental Systems Believe. American Psychologist 1991, 46:107-119.

98. Shrum LJ, Wyer RS, O'Guinn TC. The effects of television consumption on social perceptions: the use of priming procedures to investigate psychological processes. J Consum Res 1998, 24:447-458.

99. Pechmann C, Shih CF. Smoking in movies and antismoking ads before movies: effects on youth. J Mark 1999, 63:1-13.

100. Gerbner G, Gross L, Morgan M, Signorielli N. The 'mainstreaming' of America: violence profile no. 11. J Commun 1980, 30:10-29.

101. Hirsch P. Distinguishing good speculation from bad theory: rejoinder to Gerbner et al. Commun Res 1981, $8: 73-95$

102. Williams D. Virtual cultivation: online worlds, offline perceptions. J Commun 2006, 56:69-87.

103. Williamson T. Armchair philosophy, metaphysical modality, and counterfactual thinking. Proc Aristotelian Soc 2005, 105:1-23.

104. Williamson T. The Philosophy of Philosophy. Oxford: Blackwell; 2007.

105. Stalnaker R. A theory of conditionals. In: Rescher N, ed. Studies in Logical Theory, American Philosophical Quarterly. Monograph Series. Vol. 2, Oxford: Blackwell; 1968, 98-112.

106. Lewis D. Counterfactuals. Oxford: Basil Blackwell; 1973.
107. Lewis D. Counterfactual dependence and time's arrow. Nô̂s 1979, 13:455-476.

108. Edgington D. Conditionals. In: Zalta E, ed. The Stanford Encyclopedia of Philosophy (Winter 2008 Edition), 2008. Available at: http://plato.stanford. edu/archives/entries/conditionals/.

109. Arlo-Costa H. The logic of conditionals. In: Zalta E, ed. The Stanford Encyclopedia of Philosophy (Spring 2009 Edition), 2009. Available at: http://plato.stanford.edu/archives/entries/logic-condi tionals/.

110. Johnson-Laird PN. Mental Models. Cambridge: Cambridge University Press; 1983.

111. Roese NJ, Olson JM, eds. What Might Have Been: The Social Psychology of Counterfactual Thinking. Mahwah, NJ: Erlbaum; 1995.

112. Byrne R. The Rational Imagination. Cambridge: MIT Press; 2005.

113. Weisberg DS, Goodstein J. 2009. What belongs in a fictional world? J Cogn Cult 9:69-78.

114. Rafetseder E, Cristi-Vargas R, Perner J. Counterfactual reasoning: developing a sense of 'nearest possible world'. Child Dev 2010, 81:376-389.

115. Markman KD, Klein WMP, Suhr JA, eds. Handbook of Imagination and Mental Simulation. New York: Taylor \& Francis; 2009.

116. Egan A. Imagination, delusion, and self-deception. In: Bayne T, Fernandez J, eds. Delusions, Self-Deception, and Affective Influences on Belief-formation. New York: Psychology Press; 2008.

117. Coltheart M, Davies M, eds. Pathologies of Belief. Oxford: Wiley-Blackwell; 2000.

118. Gendler TS. Alief and belief. J Philos 2008, 105:634-663.

119. Gendler TS. Alief in action (and reaction). Mind Lang 2008, 23:552-585.

120. Foulkes D. Children's Dreaming and the Development of Consciousness. Cambridge, MA: Harvard University Press; 1999.

121. Ichikawa J. Dreaming and imagination. Mind Lang 2009, 24:103-121.

122. Sosa E. Dreams and philosophy. Proc Aristotelian Soc 2005, 79:7-18.

123. Sosa E. A Virtue Epistemology. Vol. 1. New York: Oxford University Press; 2007.

124. Sutton J. Dreaming. In: Calvo P, Symons J, eds. Routledge Companion to the Philosophy of Psychology. London: Routledge; 2009, 522-542.

125. Flanagan O. Dreaming Souls: Sleep, Dreams and the Evolution of the Conscious Mind. New York: Oxford University Press; 1999.

126. Gendler TS. 'Imagination' in the Stanford Encyclopedia of Philosophy, 2010. 
127. Gendler TS. On the relation between pretense and belief. In: Kieran M, Lopes DM, eds. Imagination, Philosophy, and the Arts. London: Routledge; 2003, 125-141.
128. Gendler TS. Imaginative resistance. In: Davies S, Higgins K, Hopkins R, Stecker B, eds. A Companion to Aesthetics. 2nd ed. Malden, MA: Wiley-Blackwell: John Wiley \& Sons; 2009.

\section{FURTHER READING}

Green MC, Strange JJ, Brock TC, eds. Narrative impact: Social and cognitive foundations. Mahwah, NJ: Lawrence Erlbaum Associates, Inc; 2002.

Kieran M, Lopes DM, eds. Imagination, Philosophy, and the Arts. London: Routledge; 2003.

Kind A, ed. PhilPapers: Imagination and Pretense, Available at: http://philpapers.org/browse/imagination-andpretense

Lewis D. Counterfactual dependence and time's arrow. Nô̂s 1979, 13:455-476.

Lewis C, Mitchell P, eds. Children's Early Understanding of Mind. Hillsdale, NJ: Lawrence Erlbaum; 1994.

Markman KD, Klein WMP, Suhr JA, eds. Handbook of Imagination and Mental Simulation, New York: Taylor \& Francis; 2009.

Mitchell RW, ed. Pretending and Imagination in Animals and Children. New York: Cambridge University Press.

Nichols S, ed. The Architecture of the Imagination: New Essays on Pretense, Possibility, and Fiction. Oxford: Oxford University Press; 2006.

Walton K. Morals in fiction and fictional morality. Proc Aristotelian Soc 1994, 68:27-50. 